\title{
Heterogeneous uptake of gaseous hydrogen peroxide by Gobi and Saharan dust aerosols: a potential missing sink for $\mathrm{H}_{2} \mathrm{O}_{2}$ in the troposphere
}

\author{
M. Pradhan ${ }^{1}$, G. Kyriakou ${ }^{1}$, A. T. Archibald ${ }^{1,2}$, A. C. Papageorgiou ${ }^{1}$, M. Kalberer ${ }^{1}$, and R. M. Lambert ${ }^{1}$ \\ ${ }^{1}$ Department of Chemistry, University of Cambridge, Lensfield Road, Cambridge, CB2 1EW, UK \\ ${ }^{2}$ NCAS Climate, Centre for Atmospheric Science, Department of Chemistry, University of Cambridge, Lensfield Road, \\ Cambridge, CB2 1EW, UK
}

Received: 16 April 2010 - Published in Atmos. Chem. Phys. Discuss.: 26 April 2010

Revised: 16 July 2010 - Accepted: 20 July 2010 - Published: 3 August 2010

\begin{abstract}
The first direct laboratory measurements of gaseous hydrogen peroxide uptake by authentic Gobi and Saharan dust aerosol particles as a function of relative humidity (RH) have been carried out in an entrained aerosol flow tube coupled to a chemical ionization mass spectrometer. Gobi dust shows uptake coefficients, $\gamma_{\mathrm{H}_{2} \mathrm{O}_{2}}=(3.33 \pm 0.26) \times 10^{-4}$ at $15 \% \mathrm{RH}$ rising to $\gamma_{\mathrm{H}_{2} \mathrm{O}_{2}}=(6.03 \pm 0.42) \times 10^{-4}$ at $70 \%$ $\mathrm{RH}$; the corresponding values for Saharan dust are systematically higher $\left(\gamma_{\mathrm{H}_{2} \mathrm{O}_{2}}=(6.20 \pm 0.22) \times 10^{-4}\right.$ at $15 \% \mathrm{RH}$ rising to $\gamma_{\mathrm{H}_{2} \mathrm{O}_{2}}=(9.42 \pm 0.41) \times 10^{-4}$ at $\left.70 \% \mathrm{RH}\right)$. High resolution Xray photoelectron spectroscopy (XPS) measurements of the surface chemical composition of the two mineral dust samples together with published water adsorption isotherms of their principal constituents enables rationalization of these observations, which are relevant to nighttime tropospheric chemistry. A box model study performed by incorporating the experimentally determined data set reveals that uptake of $\mathrm{H}_{2} \mathrm{O}_{2}$ onto dust can be an important loss process for this species which has been, until now, poorly constrained.
\end{abstract}

\section{Introduction}

The Gobi desert in northwest China and the Sahara desert in northern Africa are the two most important global sources of mineral dust aerosol with current estimates of between 1000$3000 \mathrm{Tg} / \mathrm{yr}$ being advected into the atmosphere (Tegen and Fung, 1994; Dentener et al., 1996; Luo et al., 2003). Dust

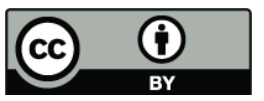

Correspondence to: R. M. Lambert (rml1@cam.ac.uk) aerosols produced from windblown soils in arid and semiarid regions can be viewed as a mixture of inorganic oxides and carbonates, possibly with some adsorbed organics and/or sulfates present (Usher et al., 2003; Hatch and Grassian, 2008). The atmospheric residence time of mineral dust aerosol depends on several factors such as meteorological conditions and the particle size distribution. Large dust particles with diameters of $100 \mu \mathrm{m}$ are only found in the vicinity of desert regions whereas small particles with diameters typically $<4 \mu \mathrm{m}$ have an atmospheric lifetime of up to several weeks (Prospero, 1999; Bauer et al., 2004). They can be transported over thousands of kilometers by individual dust storms from Africa across the Atlantic to the east coast of the United States or from Asia across the Pacific Ocean (Duce et al., 1980; Savoie and Prospero, 1982; Ott et al., 1991). During long-range transport, particles interact with various organic and inorganic atmospheric trace gas-species, and can consequently impact numerous atmospheric processes, potentially changing the chemical balance of the atmosphere through heterogeneous reactions by providing reactive surface sites (Cwiertny et. al., 2008; Hatch and Grassian, 2008). Other well-known processes include direct and indirect climate forcing (due to scattering and absorbing of incoming solar radiation) or effects on biogeochemical cycles of trace elements such as iron (Ravishankara, 1997; Kaufman et. al., 2002; Usher et al., 2003).

Mineral dust particles can act as a sink or reactive surface for a variety of atmospheric chemical species (Usher et al., 2003). Accordingly, heterogeneous reactions occurring on the surface of mineral dust aerosol particles may provide additional chemical pathways, which may account for the discrepancies between field and laboratory

Published by Copernicus Publications on behalf of the European Geosciences Union. 
measurements. During the last decade, the heterogeneous chemical kinetics of gas-phase species such as $\mathrm{SO}_{2}, \mathrm{O}_{3}$, $\mathrm{NO}_{3}, \mathrm{~N}_{2} \mathrm{O}_{5}$, and $\mathrm{HNO}_{3}$ interacting with mineral dust aerosol particles has attracted intensive study: both laboratory studies and field experiments have demonstrated the importance of this chemistry (Hanisch and Crowley, 2003; Adams et al., 2005; Karagulian and Rossi, 2005; de Reus et al., 2005; Vlasenko et al., 2006, Wagner et al., 2008; Crowley et al., 2010).

In contrast, laboratory measurements of the heterogeneous chemical kinetics of gaseous hydrogen peroxide $\left(\mathrm{H}_{2} \mathrm{O}_{2}\right)$ under realistic atmospheric conditions have not been explored thus far. $\mathrm{H}_{2} \mathrm{O}_{2}$ is an important atmospheric oxidant with a relatively short atmospheric lifetime $(\sim 1$ day $)$ and serves as a sensitive indicator for $\mathrm{HO}_{\mathrm{x}}\left(\mathrm{HO}_{2}+\mathrm{OH}\right)$ chemistry (Kuhlmann et al., 2003; Rinsland et al., 2007; Hua et al., 2008). $\mathrm{H}_{2} \mathrm{O}_{2}$ is highly water soluble, acting as an important oxidant of sulfur compounds in the aqueous phase where it may be involved in the formation of secondary organic aerosol (Hua et al., 2008). Detailed quantitative understanding of the removal of atmospheric $\mathrm{H}_{2} \mathrm{O}_{2}$ by mineral dust aerosol is therefore of importance for an accurate assessment of its lifetime, its potential impact on the tropospheric $\mathrm{HO}_{\mathrm{x}}$ family chemistry, $\mathrm{OH}$ budgets, and accordingly, ozone balance. Moreover, it is important to understand how tropospheric photochemical oxidant cycles and the behaviour of other atmospheric pollutants are affected as a consequence of heterogeneous reactions of $\mathrm{H}_{2} \mathrm{O}_{2}$.

To our knowledge, there is almost no information involving direct measurement of $\mathrm{H}_{2} \mathrm{O}_{2}$ uptake by authentic mineral dust aerosol particles. Due to the absence of experimental values for the heterogeneous $\mathrm{H}_{2} \mathrm{O}_{2}$ uptake coefficient $\left(\gamma_{\mathrm{H}_{2} \mathrm{O}_{2}}\right)$ on mineral dust aerosol, previous work on combined aerosol/gas-phase chemical box models and on global and regional chemistry-transport models was necessarily based on assumptions and estimates. Inevitably, substantial uncertainties arise from the lack of reliable values for uptake coefficients used in such studies. For example, in their modeling studies Zhang et al. (1994) and Phadnis and Carmichael (2000), used a value of $\gamma_{\mathrm{H}_{2} \mathrm{O}_{2}}=0.1$, whereas in similar studies by Dentener et al. (1996) and Martin et al. (2003), the uptake of $\mathrm{H}_{2} \mathrm{O}_{2}$ on dust was simply neglected. Other modeling studies have used widely divergent values in the range $8.0 \times 10^{-4} \leq \gamma_{\mathrm{H}_{2} \mathrm{O}_{2}} \leq 0.18$, corresponding to an upper limit and lower limit (Zhang and Carmichael, 1999; Zhu et al., 2009).

Here, we present a detailed investigation of the heterogeneous chemical kinetics of authentic mineral dust aerosol with gas-phase $\mathrm{H}_{2} \mathrm{O}_{2}$. To our knowledge, this is the first laboratory study of the heterogeneous uptake kinetics of gaseous $\mathrm{H}_{2} \mathrm{O}_{2}$ by authentic Gobi and Saharan desert dust aerosol particles over a wide range of relative humidity pertinent to the troposphere. Additionally, we explore the potential impact of heterogeneous losses of $\mathrm{H}_{2} \mathrm{O}_{2}$ on tropospheric chemistry by means of a box model study that incorporates our own experimentally determined data set.

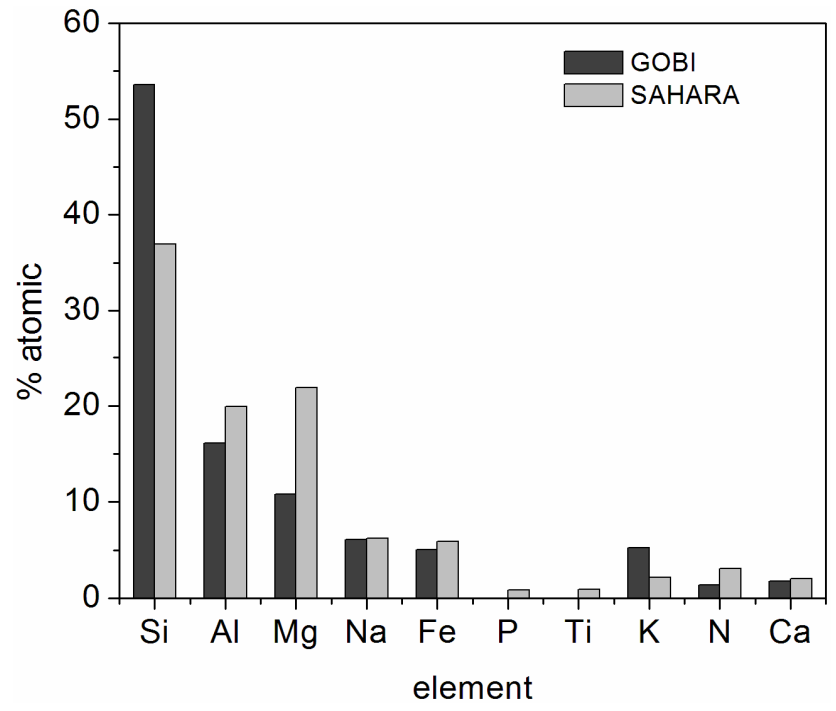

Fig. 1. Composition of Saharan and Gobi dust aerosol, as determined by high resolution XPS.

\section{Experimental}

Experiments were carried out in an aerosol flow tube (AFT) coupled to a chemical ionization mass spectrometer (CIMS) for the detection of $\mathrm{H}_{2} \mathrm{O}_{2}$. The experimental set-up and measurement procedure have been described in detail in our recent publication (Pradhan et al., 2010) and are summarized below briefly in Sect. 2.2 .

\subsection{Composition of dust aerosols: $\mathrm{X}$-ray photoelectron spectroscopy}

Two types of authentic desert dust aerosols were used: the Saharan dust originates from Cape Verde Islands and is characteristic of mineral dust aerosol transported from the western Sahara, whereas Gobi sand was collected from the Khongoryn Els in Mongolia (central China) and was mechanically ground and sieved to $\leq 1 \mu \mathrm{m}$ diameter. The chemical composition of both dusts was determined by high resolution X-ray photoelectron spectroscopy (XPS) (Fig. 1) a technique that provides information about surface as opposed to bulk chemical composition, the property that actually matters in regard to surface chemical behaviour.

Details of sample preparation and handling, instrumentation, data acquisition, quantification and representative spectra are given in the supporting information. Figure 1 summarizes the quantified results obtained for both types of sample. It is evident that the surface composition of the two samples is broadly similar, though certain minor components show large differences in relative concentrations. Silica and alumina are the most abundant constituents in both samples, as would be expected; interestingly, the Saharan dust contains a small amount of Ti present as $\mathrm{TiO}_{2}$ whereas this material 
is undetectable in the Gobi sample. Moreover, both samples contain $\mathrm{Fe}$ as $\mathrm{Fe}_{2} \mathrm{O}_{3}$ : the significance of these findings will be discussed below. In passing we note that similar Saharan dust samples, also collected from the Cape Verde islands, were used by Hanisch and Crowley (2003): their bulk composition, determined by energy dispersive X-ray spectroscopy, was similar to the surface composition we observed by XPS.

\subsection{Generation and characterization of dust aerosol}

Aerosol of either Gobi or Saharan dust was generated from an aqueous suspension using a commercial atomizer (TSI 3076). In view of the XPS results which show that the surfaces of the dust particles consist of insoluble inorganic compounds, this procedure is not expected to change significantly the chemical characteristics of the dusts. The aerosol relative humidity $(\mathrm{RH})$ was controlled using a silica gel drying unit in series with a humidifier system and monitored with an accuracy of $\pm 2 \%$ at the inlet to the AFT with a commercial hygrometer (Vaisala HMP 143A). The size distributions of the aerosol particles were characterized by a differential mobility analyzer (DMA, Hauke model EMS VIE-08) with a Faraday cup electrometer as the detector. Scans over mobility diameters ranging from $0.01-1 \mu \mathrm{m}$ produced a size distribution from which total surface areas were determined. Prior to entering the DMA or AFT, aerosol particles passed through a cut-off Berner cascade impactor to remove particles of diameters greater than $1 \mu \mathrm{m}$. The particle number density and aerosol surface area both remained constant for the two different dusts to within $5 \%$ over the time of a kinetic run $(\leq 1 \mathrm{~h})$. Furthermore, the particle size distributions for both dusts remained constant with increasing the RH in the range $15-70 \%$.

Typical size distributions of the dust particles are depicted in Fig. 2. Gobi dust exhibits a bimodal distribution whereas that of the Saharan dust is monomodal. The origin of the bimodal distribution of the Gobi dust is not clear. We may speculate that the bimodal distribution is a consequence of agglomeration of the smaller particles in the atomizer suspension. The insets in Fig. 2 show the distributions in terms of surface area $\left(\mu \mathrm{m}^{2} \mathrm{~cm}^{-3}\right)$ given as the function $\pi D^{2} \frac{d N}{d \ln D}$ obtained for each of the 34 size fractions measured in the DMA. The particle diameters at the maximum in the surface area distribution are $0.40 \mu \mathrm{m}$ and $0.17 \mu \mathrm{m}$ for the Gobi and Saharan dusts, respectively.

The non-spherical shape of mineral dust particles induces a systematic error when the electrical mobility diameters of the DMA are used to estimate the particle surface areas, which can be as high as a factor of 1.5 to 2 (Wagner et al., 2008; Hinds, 1999). However, the geometric shape of the mineral dust particles used in this study was not determined and the values reported here are based on mobility equivalent diameters throughout the manuscript. It is assumed that the two types of dust particles have roughly the same non-

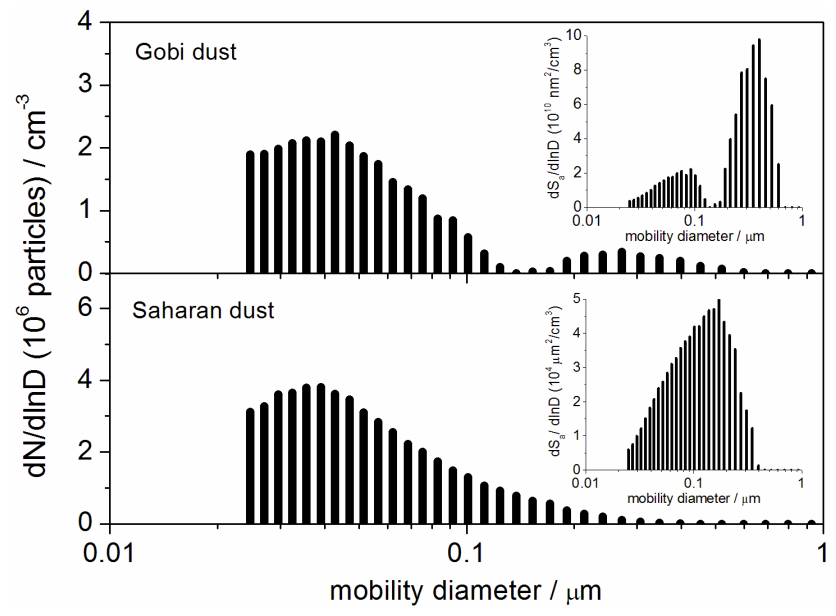

Fig. 2. Typical size distributions of dust aerosol particles used to study the heterogeneous reaction with gaseous hydrogen peroxide. The distributions result from atomizing a $4.0 \mathrm{wt} \%$ suspension of dust in water. Particle diameters at the maximum in the surface area distribution are $0.08 \mu \mathrm{m}$ and $0.40 \mu \mathrm{m}$ for the Gobi (bimodal) and $0.17 \mu \mathrm{m}$ for the Saharan dusts (monomodal).

spherical shapes and thus relative differences observed between the two types of dust should not be affected significantly by this uncertainty.

\subsection{Aerosol Flow Tube Reactor for kinetic experiments}

The aerosol flow tube (AFT) reactor has been described in detail previously (Pradhan et al., 2010). The halocarbon wax coated AFT (length $60 \mathrm{~cm}$, ID $3 \mathrm{~cm}$ ) was maintained at ambient temperature $(295 \pm 2 \mathrm{~K})$ and pressure. Under typical measurement conditions the constant volumetric flow rate was $1.25 \mathrm{slpm}$ corresponding to an average linear flow velocity of $\sim 2.4 \mathrm{~cm} \mathrm{~s}^{-1}$; the Reynold's number and time for diffusional mixing were estimated to be $\sim 107$ and $2.4 \mathrm{~s}$, respectively. Contact times were varied by means of a sliding injector and all heterogeneous kinetic measurements were performed at contact times of 6-15 s (see Fig. 3) to ensure that data were acquired under well-mixed and fully developed laminar flow conditions.

\subsection{Generation of gas-phase $\mathrm{H}_{2} \mathrm{O}_{2}$ and detection system}

A detailed description of the generation with delivery system of gaseous $\mathrm{H}_{2} \mathrm{O}_{2}$ has been reported previously (Pradhan et al., 2010) and only operational parameters are given here. A concentrated $\mathrm{H}_{2} \mathrm{O}_{2}$ sample of $(\geq 95 \mathrm{wt} \%)$ was prepared from an aqueous solutions of $\mathrm{H}_{2} \mathrm{O}_{2}$ (Aldrich, $50 \mathrm{wt} \%$ ) for the kinetic measurements. To generate the concentrated sample, a flow of dry $\mathrm{N}_{2}$ was bubbled through the diluted aqueous solution for two days; then the $\mathrm{H}_{2} \mathrm{O}_{2}$ finger (pyrex U-tube), kept in an ice bath, was transferred to a vacuum line where the vapour pressure of $\mathrm{H}_{2} \mathrm{O}_{2}$ was monitored. The 


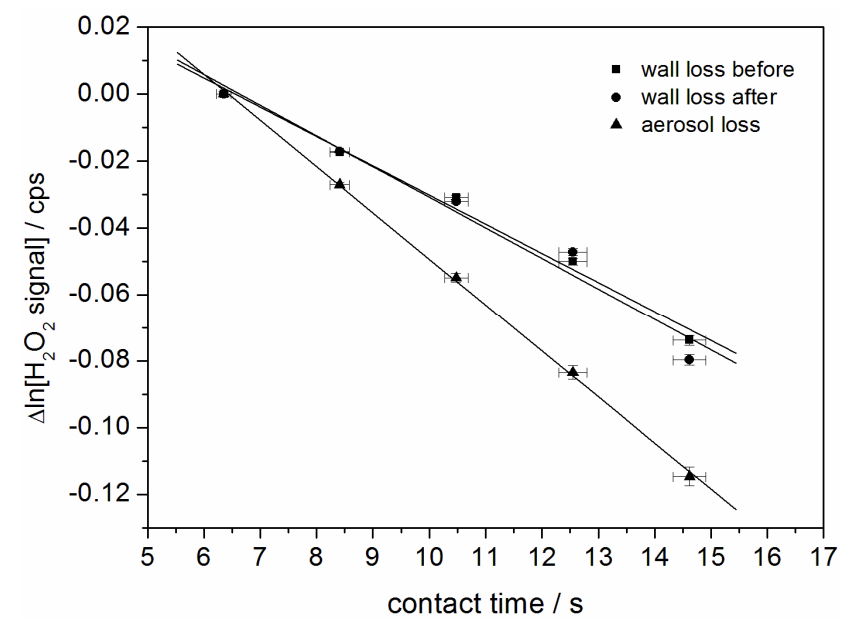

Fig. 3. An example of a heterogeneous kinetic run of $\mathrm{H}_{2} \mathrm{O}_{2}$ uptake by Gobi dust aerosol at 35\% RH in the aerosol flow tube. The lines show $2 \sigma$ error-weighted least-squares fits to the data from which first-order rate constants are determined. Error bars on the $\mathrm{H}_{2} \mathrm{O}_{2}$ signal are $2 \sigma$ standard deviation of the noise level in the measured signal. Error bars on contact times result from $\pm 2 \%$ uncertainties in the flow rate measurements.

vapour pressure of pure $\mathrm{H}_{2} \mathrm{O}_{2}$ at $273.2 \mathrm{~K}$ is 0.352 Torr as measured by Manatt and Manatt (2004). Measurement of the vapour pressure in the present case indicated that purity was $\geq 95 \mathrm{wt} \% \mathrm{H}_{2} \mathrm{O}_{2}$. The $\mathrm{H}_{2} \mathrm{O}_{2}$ vapour was delivered to the experimental gas line by flowing $20 \mathrm{sccm}$ dry $\mathrm{N}_{2}$ through the cold finger at $273.2 \mathrm{~K}$ and the resulting $\mathrm{H}_{2} \mathrm{O}_{2}$ saturated flow was then mixed with a $1200 \mathrm{sccm}$ dry $\mathrm{N}_{2}$ carrier flow. A fraction of this flow $(25 \mathrm{sccm})$ was introduced into the AFT via the injector. When this flow was mixed with the main gas flow $(1000 \mathrm{sccm})$, it resulted in a typical initial flow tube concentration of $\mathrm{H}_{2} \mathrm{O}_{2} \sim 4.2 \times 10^{12}$ molecules $\mathrm{cm}^{-3}$ (169 ppbv).

$\mathrm{H}_{2} \mathrm{O}_{2}$ was detected with the CIMS (Extrel Model 150-QC) using $\mathrm{CF}_{3} \mathrm{O}^{-}(m / z=85)$ as a reagent ion. $\mathrm{CF}_{3} \mathrm{O}^{-}$was generated by flowing trace amounts of $\mathrm{CF}_{3} \mathrm{OOCF}_{3}$ in $2.0 \mathrm{slpm}$ $\mathrm{N}_{2}$ over a radioactive ${ }^{210} \mathrm{Po}$ source into the chemical ionization region. The use of $\mathrm{CF}_{3} \mathrm{O}^{-}$for sensitive and selective CIMS detection of $\mathrm{H}_{2} \mathrm{O}_{2}$ was first demonstrated by Crounse et al. (2006) and subsequently used by ourselves for kinetic measurements (Pradhan et al., 2010). $\mathrm{H}_{2} \mathrm{O}_{2}$ was monitored as the cluster ion $\mathrm{CF}_{3} \mathrm{O}^{-} \cdot \mathrm{H}_{2} \mathrm{O}_{2}$ detected at $m / z=119$. The mass spectrometer was modified by incorporation of a collisional dissociation chamber (CDC) after the ion source region: this allowed sensitive detection of the target cluster ion of $\mathrm{CF}_{3} \mathrm{O}^{-} \cdot \mathrm{H}_{2} \mathrm{O}_{2}$, free from any higher cluster ions of the type $\mathrm{CF}_{3} \mathrm{O}^{-} \cdot\left(\mathrm{H}_{2} \mathrm{O}\right)_{n}$. The typical CIMS detection limit for $\mathrm{H}_{2} \mathrm{O}_{2}$ was estimated to be $\sim 1.6 \times 10^{11}$ molecules $\mathrm{cm}^{-3}$ ( $6 \mathrm{ppbv})$ at the $1 \sigma$ standard deviation noise level with respect to the baseline under an initial flow tube concentration of $\mathrm{H}_{2} \mathrm{O}_{2} \sim 4.2 \times 10^{12}$ molecules $\mathrm{cm}^{-3}$.

\section{Results and discussion}

\subsection{Heterogeneous kinetic measurements on Gobi dust aerosol}

The kinetic experiments were performed in the AFT in which the contact or reaction time between the aerosol and $\mathrm{H}_{2} \mathrm{O}_{2}$ were controlled by a sliding injector. The first order heterogeneous rate coefficient for loss of $\mathrm{H}_{2} \mathrm{O}_{2}$ solely to the aerosol particles, $k_{\text {aerosol }}$ is defined by

$k_{\text {aerosol }}=\frac{d\left[\mathrm{H}_{2} \mathrm{O}_{2}\right]}{d t\left[\mathrm{H}_{2} \mathrm{O}_{2}\right]}=\gamma_{\mathrm{H}_{2} \mathrm{O}_{2}} \frac{\langle c\rangle}{4} S_{a}$.

where $S_{a}$ is the total surface area of the aerosol particles per unit volume $\left(\mathrm{cm}^{2} \mathrm{~cm}^{-3}\right)$ as calculated from the DMA measurements, $\langle c\rangle$ is the mean molecular velocity of $\mathrm{H}_{2} \mathrm{O}_{2}$ gas molecules $\left(\mathrm{cm} \mathrm{s}^{-1}\right)$ and $\gamma_{\mathrm{H}_{2} \mathrm{O}_{2}}$ is the uptake coefficient. It should be noted that the aerosol surface areas reported here are based on mobility equivalent diameters as measured by the DMA and that non-spherical properties are not taken into account (see Sect. 2.2). Figure 3 illustrates typical results from a kinetic run of $\mathrm{H}_{2} \mathrm{O}_{2}$ uptake by Gobi dust aerosol particles $\left[S_{a}=(1.09 \pm 0.05) \times 10^{-3} \mathrm{~cm}^{2} \mathrm{~cm}^{-3}\right]$ at $35 \% \mathrm{RH}$ and initial $\left[\mathrm{H}_{2} \mathrm{O}_{2}\right] \approx 4.2 \times 10^{12}$ molecules $\mathrm{cm}^{-3}$ in the AFT with a $\mathrm{H}_{2} \mathrm{O}_{2}$ sensitivity of $\sim 5 \mathrm{cps} / \mathrm{ppbv}$. In converting mobility equivalent diameters to surface areas it is assumed that the particles have spherical shape. The kinetics of $\mathrm{H}_{2} \mathrm{O}_{2}$ loss to the walls was measured both prior to and following the aerosol kinetic run. First-order rate constants, $k_{\text {wall }}$ for loss in the absence of aerosol and $k_{\text {total }}$ for losses to both aerosol and wall (i.e. $k_{\text {total }}=k_{\text {aerosol }}+k_{\text {wall }}$ ), are determined from the gradients of weighted linear least square fits to the data sets. The first-order rate constant $\left.k_{\text {total }}=k_{\text {aerosol }}+k_{\text {wall }}\right)$ was then corrected for axial diffusion using the iterative method of Brown (1978) (see e.g., Wagner et al., 2008). In this correction the gas-phase diffusion constant for $\mathrm{H}_{2} \mathrm{O}_{2}$ was taken as $0.184 \mathrm{~cm}^{2} \mathrm{~s}^{-1}$ as calculated by McMurtrie and Keyes (1978). The $\mathrm{H}_{2} \mathrm{O}_{2}$ uptake coefficient, $\gamma_{\mathrm{H}_{2} \mathrm{O}_{2}}$ was then determined from the rate constant, $k_{\text {aerosol }}=\left(k_{\text {total }}-k_{\text {wall }}\right)$ by using Eq. (1).

The results shown in Fig. 3 for the Gobi dust aerosol yield a value of $\gamma_{\mathrm{H}_{2} \mathrm{O}_{2}}=(3.51 \pm 0.28) \times 10^{-4}$. However, it should be mentioned that the value of the experimentally determined uptake coefficient $\left(\gamma_{\exp }\right)$ obtained in this way can lead to an underestimation of the true uptake coefficient $\left(\gamma_{\text {true }}\right)$. This effect resulting from gas phase diffusion can be corrected for, as described by the method of Fuchs and Sutugin (1970) using:

$$
\begin{aligned}
& \frac{1}{\gamma_{\text {true }}}=\frac{1}{\gamma_{\exp }}-\frac{0.75+0.283 K_{n}}{K_{n}\left(K_{n}+1\right)} \\
& K_{n}=\frac{3 D_{g}}{\langle c\rangle r_{s w}}
\end{aligned}
$$

where $D_{g}$ is the gas-phase diffusion coefficient of $\mathrm{H}_{2} \mathrm{O}_{2}, r_{s w}$ is the radius of the particle at the maximum of the surface 


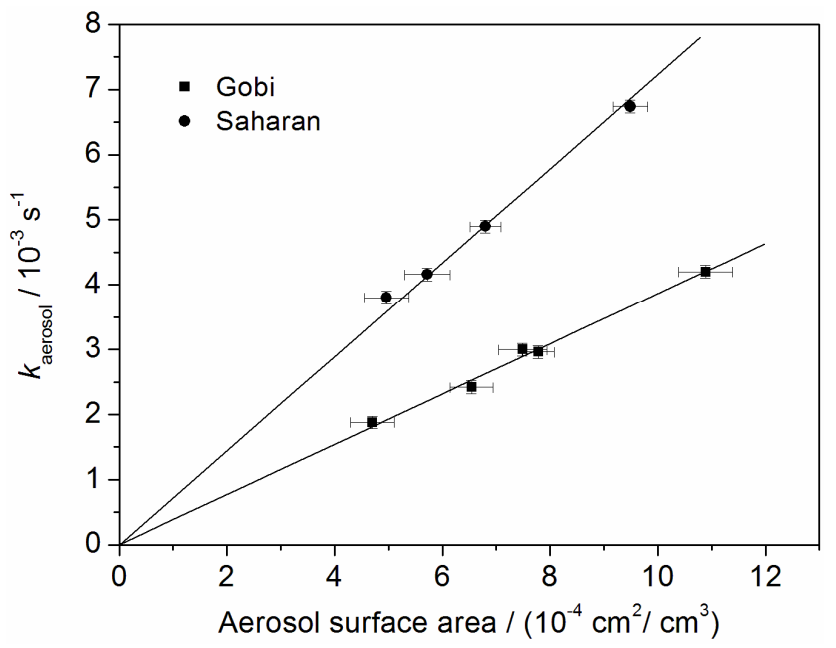

Fig. 4. Aerosol surface area, $S_{a}$, versus the first-order rate constants for loss of $\mathrm{H}_{2} \mathrm{O}_{2}$ to the aerosol $k_{\text {aerosol at } 35 \%}$ RH. The calculated uptake coefficients from the gradients of this plot are $\gamma_{\mathrm{H}_{2} \mathrm{O}_{2}}=(3.63 \pm 0.24) \times 10^{-4}$ for the Gobi dust and $\gamma_{\mathrm{H}_{2} \mathrm{O}_{2}}=(6.76 \pm 0.22) \times 10^{-4}$ for the Saharan dust. The lines represent $2 \sigma$ error-weighted least-squares fits forced through the origin.

area weighted size distribution and $K_{n}$ is the Knudsen number. We estimated that this correction is negligible $(<1 \%)$ over the entire aerosol size range $(0.01-1 \mu \mathrm{m})$ and for the relatively small reaction probabilities we observed in all kinetic runs. We therefore neglect the diffusion correction and all uptake coefficients reported here are derived solely from the Eq. (1). Additionally, the effect of varying $\mathrm{H}_{2} \mathrm{O}_{2}$ concentration was investigated by performing measurements over the range of $\sim(3.5-8.2) \times 10^{12}$ molecules $\mathrm{cm}^{-3}$; no significant dependence of $\mathrm{H}_{2} \mathrm{O}_{2}$ uptake on the $\mathrm{H}_{2} \mathrm{O}_{2}$ concentration was observed within the experimental error. Experimental constraints imposed by the difficulty of handling hydrogen peroxide vapour prevented investigation of a wider range of $\mathrm{H}_{2} \mathrm{O}_{2}$ concentrations, which might have given additional insight into the reaction mechanism.

\subsection{Surface area dependence of heterogeneous rate constants}

To check the validity of the observed first order kinetics, we performed kinetic measurements in which the aerosol surface area was varied at a constant RH. This was achieved by varying the atomizer flow mixed into the humidified bulk $\mathrm{N}_{2}$ flow. Figure 4 displays a plot of the retrieved heterogeneous rate constant $\left(k_{\text {aerosol }}\right)$ versus aerosol surface area $\left(S_{a}\right)$ at $35 \% \mathrm{RH}$ and $\left[\mathrm{H}_{2} \mathrm{O}_{2}\right] \sim 4.2 \times 10^{12}$ molecules $\mathrm{cm}^{-3}$ in the AFT. A linear relationship with a gradient of $\gamma_{\mathrm{H}_{2} \mathrm{O}_{2}} \frac{\langle c\rangle}{4}$ was found for both dust aerosols. This demonstrates that the observed kinetics are first order in surface area and free from systematic errors. The gradient of the linear fits yield uptake coefficients $\gamma_{\mathrm{H}_{2} \mathrm{O}_{2}}=(3.63 \pm 0.24) \times 10^{-4}$ for the Gobi

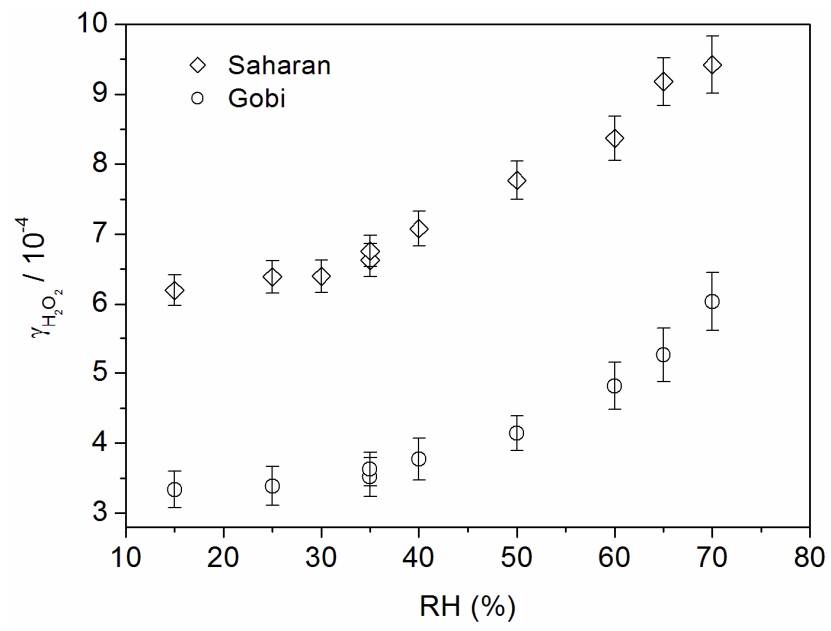

Fig. 5. Variation of uptake coefficients for $\mathrm{H}_{2} \mathrm{O}_{2}$ with relative humidity for the Gobi and Saharan dust samples. Error bars are $2 \sigma$ statistical. The additional data points at $35 \%$ RH for both dusts are calculated from the data shown in Fig. 4.

dust and $\gamma_{\mathrm{H}_{2} \mathrm{O}_{2}}=(6.76 \pm 0.22) \times 10^{-4}$ for the Saharan dust at $35 \% \mathrm{RH}$ in excellent agreement with the measurements made using a single surface area as a function of RH shown in Fig. 5. Measurements at longer contact times could yield information regarding deviation from first order kinetics and insight into whether or not the overall process was catalytic. However such observations were precluded by experimental constraints.

\subsection{Humidity dependence of $\mathrm{H}_{2} \mathrm{O}_{2}$ uptake on Gobi and Saharan dusts}

Uptake coefficients were measured over a wide range of relative humidity $(15 \%-70 \%)$ relevant to the troposphere. It is apparent from Fig. 5 that the uptake coefficients, $\gamma_{\mathrm{H}_{2} \mathrm{O}_{2}}$, of both dusts initially increases slowly with $\mathrm{RH}$ and then more rapidly for $\mathrm{RH} \geq 30 \%$. Such positive correlations of $\gamma$ with $\mathrm{RH}$ have been reported previously, for example in the case of $\mathrm{HNO}_{3}$ on Arizona Test Dust (ATD) (Vlasenko et al., 2006). As expected, both dust samples are composed mainly of silica, alumina and magnesia (Fig. 1) accompanied by smaller amounts of other oxidic materials. Moreover, the water adsorption isotherms of $\mathrm{SiO}_{2}, \mathrm{Al}_{2} \mathrm{O}_{3}$ and $\mathrm{MgO}$ have been accurately measured at $296 \mathrm{~K}$ over the $\mathrm{RH}$ range $0-98 \%$ (Usher et al., 2003). Interestingly, these data show initial Langmuir-like water uptake with monolayer completion occurring at $\sim 30 \% \mathrm{RH}$ in every case. Thereafter, multilayer formation commences, but the rate of accumulation of these higher layers is markedly dependent on the oxide in question: for example, it is much faster on $\mathrm{SiO}_{2}$ than on $\mathrm{MgO}$ (Usher et al., 2003). This behaviour is in striking qualitative accord with the results shown in Fig. 5. Keeping in mind the complexity of our mineral surfaces, we may offer the 
following admittedly approximate rationalization of these results. At low RH the dust surface is relatively water-free so that impinging $\mathrm{H}_{2} \mathrm{O}_{2}$ molecules encounter either "bare" pristine surface sites or those on which dissociative adsorption of $\mathrm{H}_{2} \mathrm{O}_{2}$ has occurred. The generally accepted mechanism (Lin and Gurol, 1998) for this process when taking place on oxide surfaces corresponds formally to a heterolytic cleavage of the molecule, thus:

$\mathrm{S}+\mathrm{H}_{2} \mathrm{O}_{2} \rightarrow \mathrm{S}^{+}+\mathrm{OH}^{-}+\mathrm{OH}^{\cdot}$

followed, under conditions where catalytic decomposition occurs, by a sequence of steps leading ultimately to the formation of water and oxygen. Whether or not the uptake we observe involves subsequent catalytic decomposition under our conditions, cannot be determined from the present measurements.

In these circumstances, the different chemical compositions of the two types of dust inevitably results in significantly different values of $\gamma_{\mathrm{H}_{2} \mathrm{O}_{2}}$. At $\mathrm{RH} \sim 30 \%$ water multilayers nucleate and start to spread to varying extents on all the solid phases present (Usher et al., 2003) and $\gamma_{\mathrm{H}_{2} \mathrm{O}_{2}}$ increases as hydrogen peroxide molecules now impinge on a patchy surface where $\mathrm{H}_{2} \mathrm{O}_{2}$ uptake into the growing islands of liquid-like water acts to enhance the net uptake coefficient. The approximately constant difference in $\gamma$ values for the two dusts that persists up to the highest $\mathrm{RH}$ accessible in our experiments (70\%) is understandable in that at $70 \%$ $\mathrm{RH}$ all the principal dust components are still only partially covered by multilayers. Knowing the aerosol particle density and specific area and the number of molecules consumed at any given time, one may estimate the fraction of the surface sites that have reacted with $\mathrm{H}_{2} \mathrm{O}_{2}$. Thus we may use the results of a particular kinetic run to estimate the coverage of $\mathrm{H}_{2} \mathrm{O}_{2}$ at (say) $15 \mathrm{~s}$ reaction time. Taking the number density of available surface sites to lie in the range $10^{18}-10^{19} \mathrm{~m}^{-2}$, yields a coverage value of between 5 and 50 percent of a monolayer, which is physically plausible and consistent with our overall view of the system. Presumably the two curves would converge at $\sim 100 \% \mathrm{RH}$ as $\mathrm{MgO}$ and $\mathrm{Al}_{2} \mathrm{O}_{3}$ multilayer uptake "catches up" with $\mathrm{SiO}_{2}$ multilayer uptake: the respective isotherms do indeed show large differences in water uptake between $70 \%$ and $100 \% \mathrm{RH}$. Related to this, we recall our earlier work on $\mathrm{H}_{2} \mathrm{O}_{2}$ uptake by $\mathrm{TiO}_{2}$ aerosols (Pradhan et al., 2010) where it was found that $\gamma_{\mathrm{H}_{2} \mathrm{O}_{2}}$ initially decreased with increasing $\mathrm{RH}$, opposite to what is found here. This likely reflects the higher intrinsic chemical reactivity of the pristine bare $\mathrm{TiO}_{2}$ surface relative to the lower reactivity of the (mainly silica and alumina) bare dust surfaces. Thus in the case of reactive $\mathrm{TiO}_{2}$ increasing surface hydration acts to retard $\mathrm{H}_{2} \mathrm{O}_{2}$ uptake whereas with relatively inactive silica/alumina growing islands of water promote $\mathrm{H}_{2} \mathrm{O}_{2}$ uptake. Consistent with this view, at high $\mathrm{RH}$ when both types of surface are extensively hydrated, the $\gamma$ values converge.
Finally, we draw attention to a potentially important issue. Saharan dust contains a significant amount of $\mathrm{TiO}_{2}$ and it is known that this material catalyzes the reduction of $\mathrm{NO}_{2}$ to nitrous acid when present as an aerosol and illuminated with near UV light under conditions pertinent to the troposphere (Gustafsson et al., 2006). The degree of hydration of certain photocatalytic materials can change dramatically upon illumination with UV light. For example $\mathrm{TiO}_{2}$ switches from hydrophobic to superhydrophilic behaviour under UV illumination. In the present case, such effects could strongly alter the distribution of liquid-like water on the mineral surface and hence the uptake of $\mathrm{H}_{2} \mathrm{O}_{2}$ and indeed those of other trace gases. Moreover, both dusts contain $\mathrm{Fe}_{2} \mathrm{O}_{3}$ (bandgap $2.0 \mathrm{eV}$ ) which also exhibits photocatalytic activity under near UV irradiation (Leland et al., 1987). Therefore it is possible that the daytime heterogeneous chemistry of both dusts could be significantly different from their nighttime chemistry.

\subsection{Implications for modeling studies}

The present results provided the first data for the uptake of $\mathrm{H}_{2} \mathrm{O}_{2}$ on authentic desert dust aerosol particles: to our knowledge, there are no other experimental findings with which to compare our data. Accordingly, in order to explore the potential impact of the heterogeneous uptake of $\mathrm{H}_{2} \mathrm{O}_{2}$ by mineral aerosol dust on tropospheric chemistry, we performed a simple box model study (see below) in which our experimentally determined RH-dependent uptake coefficients were incorporated in the calculations. Before describing these findings, we note in passing that in a recent combined field and modeling study by de Reus et al. (2005), the $\mathrm{H}_{2} \mathrm{O}_{2}$ uptake on Saharan dust plume was estimated to be in the order of $\gamma_{\mathrm{H}_{2} \mathrm{O}_{2}}=5 \times 10^{-4}$ in order to obtain agreement between calculated and observed values of $\mathrm{H}_{2} \mathrm{O}_{2}$ concentration: this estimate is in very good agreement with our experimental measurements.

The box model was written using the FACSIMILE chemical kinetics program (Curtis and Sweetenham, 1987) and was constructed using inputs from the MINATROC campaign (de Reus et al., 2005). No specific meteorological conditions were simulated; however, a parameterization was included to allow both the model temperature and $\mathrm{RH}$ to vary throughout the day ( $\min \mathrm{RH}=22 \%$, max $\mathrm{RH}=70 \%$ ). A simple photolysis procedure relating the rate of photolysis to the solar zenith angle was used in line with previous box model studies using the Master Chemical Mechanism (MCM) (Saunders et al., 2003). The model was run for a four day period using campaign average mixing ratios of a number of trace gas species as initial conditions. The model included a fairly detailed chemical mechanism based on the MCM (Saunders et al., 2003) comprising 304 species and 1072 reactions, describing the oxidation of the following compounds; $\mathrm{CH}_{4}, \mathrm{CO}, \mathrm{HCHO}$, $\mathrm{CH}_{3} \mathrm{OH}, \mathrm{CH}_{3} \mathrm{COCH}_{3}, \mathrm{C}_{3} \mathrm{H}_{8}, \mathrm{C}_{4} \mathrm{H}_{10}$ and $\mathrm{C}_{5} \mathrm{H}_{8}$. The initial conditions for the box model runs are shown in Table 1. A reference simulation was run in which no heterogeneous 
chemistry was included. This run was then used to derive the effects of inclusion of heterogeneous loss of $\mathrm{H}_{2} \mathrm{O}_{2}$ on to mineral dust. In all runs dry deposition was included following the results of de Reus (2005) who highlight its importance for, in particular, $\mathrm{H}_{2} \mathrm{O}_{2}$. The following species were dry deposited with the maximum loss rates indicated in parenthesis; $\mathrm{HNO}_{3}$ and $\mathrm{N}_{2} \mathrm{O}_{5}\left(2.5 \times 10^{-5} \mathrm{~s}^{-1}\right), \mathrm{NO}_{2}\left(1.8 \times 10^{-6} \mathrm{~s}^{-1}\right)$ and $\mathrm{O}_{3}$ and $\mathrm{H}_{2} \mathrm{O}_{2}\left(6.2 \times 10^{-6} \mathrm{~s}^{-1}\right)$. No diurnal dependence on the height of the boundary layer was included which we note may not be entirely realistic.

As we have highlighted, several previous studies have used a large range of values for the uptake coefficient of $\mathrm{H}_{2} \mathrm{O}_{2}$ onto mineral dust (Zhang et al., 1994; Phadnis and Carmichael, 2000; Zhu et al., 2009). The choice of uptake coefficient in these previous studies was unconstrained due to the lack of previous experimental data. In our box model study, heterogeneous chemistry was simply accounted for by including loss of $\mathrm{H}_{2} \mathrm{O}_{2}$ by dust using Eq. (1). As with the initialization of chemical species, we have used real world measurement data as inputs of $S_{a}$ (the dust aerosol surface area) from de Reus et al., 2005. In the model $\gamma_{\mathrm{H}_{2} \mathrm{O}_{2}}$ was calculated as a function of the observed RH dependent data for Saharan dust (Fig. 5) as it was Saharan dust that was encountered in the study of de Reus et al., (2005). Thus our calculated values of $k_{\text {aerosol }}$ vary with the changing RH throughout time in the model. The complex interplay of dust with radiation is not currently considered in our simple model, but it is duly noted that several previous studies have highlighted that dust has a dampening effect on the photolysis rates of many labile trace gases. In light of this we acknowledge that our model formulation is not entirely representative of real world conditions. However, we note that the aims of this work are to assess the first order sensitivity of the chemical system to the new measurements.

The chemistry of $\mathrm{H}_{2} \mathrm{O}_{2}$ in the reference simulation can be expressed analytically as:

$$
\begin{aligned}
& \frac{d\left[\mathrm{H}_{2} \mathrm{O}_{2}\right]}{d t}= \\
& k_{1}\left[\mathrm{HO}_{2}\right]^{2}-j_{2}\left[\mathrm{H}_{2} \mathrm{O}_{2}\right]-k_{3}[\mathrm{OH}]\left[\mathrm{H}_{2} \mathrm{O}_{2}\right]-v_{d}\left[\mathrm{H}_{2} \mathrm{O}_{2}\right]
\end{aligned}
$$

where the first term corresponds to the production of $\mathrm{H}_{2} \mathrm{O}_{2}$ from the $\mathrm{HO}_{2}+\mathrm{HO}_{2}$ self reaction. The rate constant for this reaction $\left(k_{1}\right)$ shows both bi-molecular and ter-molecular components and most notably shows significant enhancement in the presence of hydrogen bonding gases (e.g. $\mathrm{H}_{2} \mathrm{O}$, Stone and Rowley, 2005). The loss of $\mathrm{H}_{2} \mathrm{O}_{2}$ in the reference run is then accounted for by photolysis $\left(j_{2}\right)$, the reaction with $\mathrm{OH}\left(k_{3}\right)$ and dry deposition $\left(v_{d}\right)$ with kinetic data taken from the MCM (apart from $v_{d}$, see above). Equation (4) is then modified in the sensitivity tests by inclusion of the additional loss process of $\mathrm{H}_{2} \mathrm{O}_{2}$ to dust aerosol.

Dust was accounted for in the model using a single parameter, $S_{a}$. This value was maintained as a constant throughout the model runs and thus these runs highlight the effects of time integrated exposure of the chemical system to dust.
Table 1. Initial chemical and physical conditions for the box model runs.

\begin{tabular}{ll}
\hline Parameter & Value \\
\hline Temperature* & $292.0 \mathrm{~K}$ \\
Relative Humidity $(\mathrm{RH})^{*}$ & $45.0 \%$ \\
Pressure & $1000 \mathrm{hPa}$ \\
{$\left[\mathrm{H}_{2} \mathrm{O}\right]$} & $1.5 \times 10^{17}$ molecules $\mathrm{cm}^{-3}$ \\
{$\left[\mathrm{CH}_{4}\right]$} & $1.8 \mathrm{ppmv}$ \\
{$\left[\mathrm{NO}_{\mathrm{x}}\right]$} & $0.25 \mathrm{ppbv}$ \\
{$\left[\mathrm{O}_{3}\right]$} & $45.0 \mathrm{ppbv}$ \\
{$[\mathrm{CO}]$} & $100.0 \mathrm{ppbv}$ \\
{$[\mathrm{HCHO}]$} & $0.5 \mathrm{ppbv}$ \\
{$\left[\mathrm{H}_{2} \mathrm{O}_{2}\right]$} & $1.0 \mathrm{ppbv}$ \\
{$\left[\mathrm{CH}_{3} \mathrm{OOH}\right]$} & $1.0 \mathrm{ppbv}$ \\
{$\left[\mathrm{HNO}_{3}\right]$} & $0.8 \mathrm{ppbv}$ \\
{$\left[\mathrm{CH}_{3} \mathrm{OH}\right]$} & $2.0 \mathrm{ppbv}$ \\
{$\left[\mathrm{CH}_{3} \mathrm{COCH}\right]$} & $1.3 \mathrm{ppbv}$ \\
{$\left[\mathrm{C}_{3} \mathrm{H}_{8}\right]$} & $0.05 \mathrm{ppbv}$ \\
{$\left[\mathrm{C}_{4} \mathrm{H}_{10}\right]$} & $0.03 \mathrm{ppbv}$ \\
{$\left[\mathrm{C}_{5} \mathrm{H}_{8}\right]$} & $0.15 \mathrm{ppbv}$ \\
\hline
\end{tabular}

* vary throughout the model run.

Hence these runs mimic a dust laden air parcel undergoing photochemical aging. It should be noted that representing dust in this way may have some effect on the results as the model does not take into account the possibility that as dust is aged, and in the absence of decomposition of adsorbed hydrogen peroxide, multilayers of $\mathrm{H}_{2} \mathrm{O}_{2}$ could in principle form, this affecting the kinetics. However, peroxide multilayers would appear to be an unphysical condition examination of which is beyond the scope of our experiments. Accordingly, the results calculated here represent an upper limit. Several sensitivity tests were performed in which the input $S_{a}$ was varied from a minimum of $15 \mu \mathrm{m}^{2} \mathrm{~cm}^{-3}$ to a maximum of $200 \mu \mathrm{m}^{2} \mathrm{~cm}^{-3}$ representing the range of measured values quoted by de Reus et al., (2005). The results of these tests are shown in Figs. 6 and 7, relative to the reference run in which no heterogeneous loss of $\mathrm{H}_{2} \mathrm{O}_{2}$ was included (see supplementary information for profiles of $\mathrm{H}_{2} \mathrm{O}_{2}$ and other trace gases as a function of time for the model runs). The results of the simulations highlight that heterogeneous uptake of $\mathrm{H}_{2} \mathrm{O}_{2}$ on dust can act as an important loss process of $\mathrm{H}_{2} \mathrm{O}_{2}$, currently not considered in many models. In the base run the loss of $\mathrm{H}_{2} \mathrm{O}_{2}$ is dominated by dry deposition to the surface (assuming an average $v_{d}=0.5 \mathrm{~cm} \mathrm{~s}^{-1}$ ) with the contributions from photolysis and the reaction with $\mathrm{OH}$ being roughly equal. Figure 6 shows that with reasonably high levels of dust loading (daily average $S_{a} \leq 100 \mu \mathrm{m}^{2} \mathrm{~cm}^{-3}$ ), there are increases in the loss of $\mathrm{H}_{2} \mathrm{O}_{2}$ of $\sim 10 \%$ and greater. This increase in $\mathrm{H}_{2} \mathrm{O}_{2}$ removal leads to decreases in the $\mathrm{H}_{2} \mathrm{O}_{2}$ lifetime with respect to dust of a factor of $\sim 4$. In Fig. 7 the effects of inclusion of $\mathrm{H}_{2} \mathrm{O}_{2}$ uptake are shown as a function of 


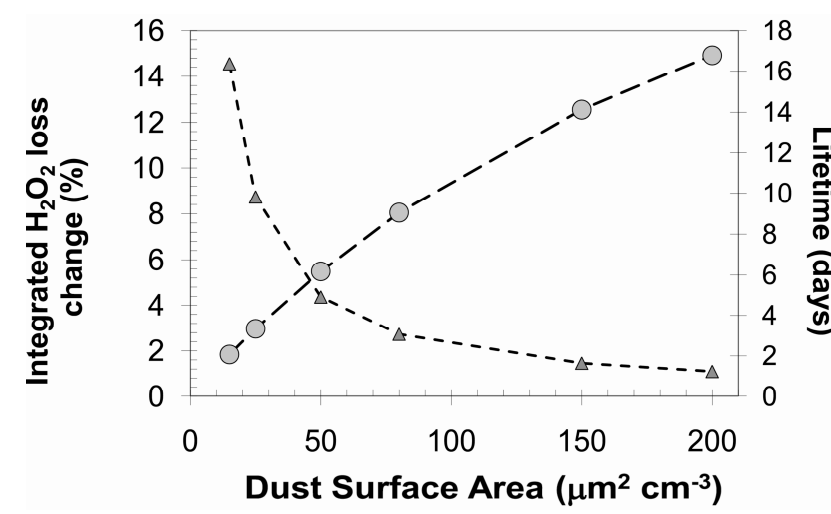

Fig. 6. The increase in $\mathrm{H}_{2} \mathrm{O}_{2}$ loss as a function of increasing dust exposure relative to the control run with no heterogeneous loss (filled circles). The $e$-folding lifetime of $\mathrm{H}_{2} \mathrm{O}_{2}$ is also shown with respect to dust exposure (filled triangles).

$S_{a}$ for a range of important trace gas species. The results are presented as the relative difference (\%) after the second day of model integration. From Fig. 7 it is clear that the single biggest effect of inclusion of this extra loss term for $\mathrm{H}_{2} \mathrm{O}_{2}$ is that the model simulated $\mathrm{H}_{2} \mathrm{O}_{2}$ concentrations are substantially reduced (up to $\sim 40 \%$ after two days). The effects on total organic peroxy radicals $\left(\Sigma \mathrm{RO}_{2}\right), \mathrm{OH}, \mathrm{O}_{3}$ and $\mathrm{NO}_{\mathrm{x}}$ are all smaller than $\pm 5 \%$.

Finally, a further run was performed whereby the uptake of $\mathrm{H}_{2} \mathrm{O}_{2}$ into the aqueous phase was included. The role of $\mathrm{H}_{2} \mathrm{O}_{2}$ as an in cloud oxidant has been known for several decades and it is widely acknowledged that $\mathrm{H}_{2} \mathrm{O}_{2}$ is one of the principal oxidants involved in conversion of $\mathrm{SO}_{2}$ to $\mathrm{SO}_{4}^{(-2)}$. In this run again only perturbations to the chemistry of $\mathrm{H}_{2} \mathrm{O}_{2}$ are considered with the aqueous uptake acting as an additional loss process for Eq. (4). Data for the aqueous uptake were based on the work of Redington et al. (2009). Considering a cloud fraction of $30 \%$ and a cloud liquid water content of $0.3 \mathrm{~g} \mathrm{~m}^{-3}$ (typical of cumulus clouds) the aqueous phase uptake outweighs the other loss processes by a further $26 \%$. The model simulated $\mathrm{H}_{2} \mathrm{O}_{2}$ mixing ratios are thus substantially reduced, being $\sim 60 \%$ lower than the reference run after two days. Thus under these conditions the effects of aqueous removal $\mathrm{H}_{2} \mathrm{O}_{2}$ are a factor of $\sim 2$ greater than for heterogeneous loss onto dust. However, we note that in many of the regions where severe dust events occur the local meteorology may dictate that cloud formation is weak and so this aqueous phase loss shall be much less important.

\section{Conclusions}

The uptake coefficients of hydrogen peroxide on Saharan and Gobi mineral aerosol dusts are significantly different and vary markedly with relative humidity. They are very different from either the much bigger or the negligible values that

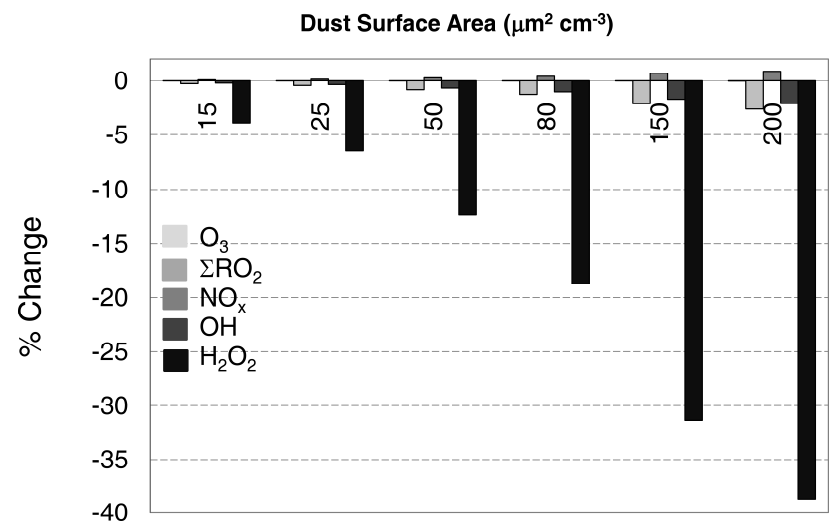

Fig. 7. The effects of including reactive uptake of $\mathrm{H}_{2} \mathrm{O}_{2}$ as a function of dust loading for a range of trace gases.

have been assumed in earlier modeling studies. Using these experimental values in a simple box model indicates that the loss of $\mathrm{H}_{2} \mathrm{O}_{2}$ to dust aerosol may present an important additional loss process for $\mathrm{H}_{2} \mathrm{O}_{2}$. This process is dependent on the simulated dust loading (in our case the dust aerosol surface area) and increases strongly with increasing loading. Under very dusty conditions we have calculated that dust accounts for $\sim 75 \%$ of the loss of $\mathrm{H}_{2} \mathrm{O}_{2}$ and this term leads to an $\sim 15 \%$ increase in the total rate of loss of $\mathrm{H}_{2} \mathrm{O}_{2}$ compared to a reference simulation. This quickly leads to significant reductions in the modeled mixing ratios of $\mathrm{H}_{2} \mathrm{O}_{2}$ after only a few days.

In the light of the measured surface chemical composition of the two mineral dusts and given the water adsorption isotherms of their principal constituents, it is possible to rationalize our observations, which are characteristic of their nighttime tropospheric chemistry. The presence of relatively minor but strongly UV-photoactive components points to the possibility that the daytime chemistry may be significantly different.

\section{Supplementary material related to this article is available online at: http://www.atmos-chem-phys.net/10/7127/2010/ acp-10-7127-2010-supplement.pdf.}

Acknowledgements. We are very grateful to Helge Willner, Bergische Universität, Wuppertal, Germany for kindly providing the $\mathrm{CF}_{3} \mathrm{OOCF}_{3}$ used in this study. We would like to thank Tony Cox for his kind provision of the Saharan dust sample and Mette High for collecting the Gobi sample used for measurements. M. P. acknowledges a post-doctoral research funding by the Isaac Newton Trust, Trinity College, Cambridge. A. T. A wishes to thank NCAS Climate for funding. G. K. and A. C. P. acknowledge financial support from the UK Engineering and Physical Sciences Research Council.

Edited by: J. N. Crowley 


\section{References}

Adams, J. W., Rodriguez, D., and Cox, R. A.: The uptake of $\mathrm{SO}_{2}$ on Saharan dust: a flow tube study, Atmos. Chem. Phys., 5, 26792689, doi:10.5194/acp-5-2679-2005, 2005.

Bauer, S. E, Balkanski, Y., Schulz, M., Hauglustaine, D. A., and Dentener, F.: Global modeling of heterogeneous chemistry on mineral aerosol surfaces: Influences on tropospheric ozone chemistry and composition to observations, J. Geophys. Res., 109, D02304, doi:10.1029/2003JD003868, 2004.

Brown, R. L.: Tubular flow reactors with first-order kinetics, J. Res. Nat. Bur. Standards, 83, 1-8, 1978.

Crounse, J. D., Mckinney, K. A., Kwan, A. J., and Wennberg, P. O.: Measurement of gas-phase hydroperoxides by chemical ionization mass spectrometry, Anal. Chem., 78, 6726-6732, 2006.

Crowley, J. N., Ammann, M., Cox, R. A., Hynes, R. G., Jenkin, M. E., Mellouki, A., Rossi, M. J., Troe, J., and Wallington, T. J.: Evaluated kinetic and photochemical data for atmospheric chemistry: Volume V-heterogeneous reactions on solid substrates, Atmos. Chem. Phys. Discuss., 10, 5233-5564, doi:10.5194/acpd10-5233-2010, 2010.

Curtis A. R. and Sweetenham, W. P.: Facsimile Users Manual; Computer Science and Systems Division, H. L., Ed.; United Kingdom Atomic Energy Authority: Oxford, UK, 1987.

Cwiertny, D. M., Young, M. A., and Grassian, V. H.: Chemistry and photochemistry of mineral dust aerosol, Annu. Rev. Phys. Chem., 59, 27-51, 2008.

Dentener, F. J., Carmichael, G. R., Zhang, Y., Leliveld, J., and Crutzen, P. J.: Role of mineral aerosol as a reactive surface in the global troposphere, J. Geophys. Res., 101, 22869-22889, 1996.

de Reus, M., Fischer, H., Sander, R., Gros, V., Kormann, R., Salisbury, G., Dingenen, R.V., Williams, J., Zollner, M., and Lelieveld, J.: Observations and model calculations of trace gas scavenging in a dense Saharan dust plume during MINATROC, Atmos. Chem. Phys., 5, 1787-1803, doi:10.5194/acp-5-17872005, 2005.

Duce, R. A., Unni, C. K., Ray, B. J., Prospero, J. M., and Merrill, J. T.: Long-range atmospheric transport of soil dust from Asia to the Tropical North Pacific: Temporal Variability, Science, 209, 1522-1524, 1980.

Fuchs, N. A. and Sutugin, A. G.: Highly dispersed aerosols, Ann Arbor Sci., Ann Arbor, 1970.

Gustafsson, R. J, Orlov, A., Griffiths, P. T., Cox, R. A., and Lambert, R. M.: Reduction of $\mathrm{NO}_{2}$ to nitrous acid on illuminated titanium dioxide aerosol surfaces: implications for photocatalysis and atmospheric chemistry, Chem. Commun., 37 3936-3938, 2006.

Hanisch, F. and Crowley, J. N.: Ozone decomposition on Saharan dust: An experimental investigation, Atmos. Chem. Phys., 3, 119-130, doi:10.5194/acp-3-119-2003, 2003.

Hatch, C. D. and Grassian, V. H.: 10th Anniversary Review: Applications of analytical techniques in laboratory studies of the chemical and climatic impacts of mineral dust aerosol in the Earth's atmosphere, J. Environ. Monit., 10, 919-934, 2008.

Hinds, W. C.: Aerosol Technology: Properties, Behavior, and Measurement of Airborne Particles, John Wiley \& Sons, New York, USA, 51-53, 1999.

Hua, W., Chen, Z. M., Jie, C. Y., Kondo, Y., Hofzumahaus, A., Takegawa,N., Chang, C. C., Lu1, K. D., Miyazaki, Y., Kita, K., Wang, H. L., Zhang, Y. H., and Hu, M.: Atmospheric hydrogen peroxide and organic hydroperoxides during PRIDE-PRD'06, China: their concentration, formation mechanism and contribution to secondary aerosols, Atmos. Chem. Phys., 8, 6755-6773, doi:10.5194/acp-8-6755-2008, 2008.

Karagulian, F. and Rossi, M. J.: The heterogeneous chemical kinetics of $\mathrm{NO}_{3}$ on atmospheric mineral dust surrogates, Phys. Chem. Chem. Phys., 7, 3150-3162, 2005.

Kaufman, Y. J., Tanre, D., and Boucher, O.: A satellite view of aerosols in the climate system, Nature, 419, 215-223, 2002.

Kuhlmann, R. V., Lawrence, M. G., and Crutzen, P. J.: A model for studies of tropospheric ozone and nonmethane hydrocarbons: Model evaluation of ozone-related species. J. Geophys. Res., 108(D23), 4729, doi:10.1029/2002JD00, 2003.

Leland, J. K. and Bard, A. J.: Photochemistry of colloidal semiconducting iron oxide polymorphs, J. Phys. Chem., 91, 5076-5083, 1987.

Lin, S. S. and Gurol, M. D.: Catalytic decomposition of hydrogen peroxide on Iron Oxide: kinetics, mechanism, and implications, Environ. Sci. Technol., 32, 1417-1423, doi:10.1021/es970648k, 1998.

Luo, C., Mahowald, N. M., and del Corral, J.: Sensitivity study of meteorological parameters on mineral aerosol mobilization, transport and distribution, J. Geophys. Res., 108, 4447, doi:10.1029/2003JD003483, 2003.

Manatt, S. L. and Manatt, M. R. R.: On the analyses of mixture vapor pressure data: The hydrogen peroxide/ water system and its excess thermodynamic functions, Chem. Eur. J., 10, 65406557, 2004.

Martin, R. V., Jacob, D. J., Yantosca, R. M., Chin, M., and Ginoux, P.: Global and regional decrease in tropospheric oxidants from photochemical effects of aerosols, J. Geophys. Res., 108(D3), 4097, doi:10.1029/2002JD002622, 2003.

McMurtrie, R. L. and Keyes, F. G.: A measurement of the diffusion coefficient of hydrogen peroxide vapor into air, J. Am. Chem. Soc., 70(11), 3755-3758, 1948.

Ott, S. T., Ott, A, Martin, D. W., and Young, J. A.: Analysis of transAtlantic Saharan dust outbreak based on satellite and GATE data, Mon. Weather Rev., 119, 1832-1850, 1991.

Phadnis, M. J. and Carmichael, G. R.: Numerical investigation of the influence of mineral dust on the tropospheric chemistry of East Asia, J. Atoms. Chem., 36, 285-323, 2000.

Pradhan, M., Kalberer, M., Griffiths, P. T., Braban, C. F., Pope, F. D., Cox, R. A., and Lambert, R. M.: Uptake of gaseous hydrogen peroxide by submicrometer titanium dioxide aerosol as a function of relative humidity, Environ. Sci. Technol., 44, 1360-1365, 2010.

Prospero, J. M.: Long range transport of mineral dust in the global atmosphere: Impact of African dust on the environment of the southeastern United States, Proc, Natl. Acad. Sci. USA, 96, 3396-3403, 1999.

Ravishankara, A. R.: Heterogeneous and multiphase chemistry in the troposphere. Science, 276, 1058-1065, 1997.

Redington, A. L., Derwent, R. G., Witham, C. S., and Manning, A. J.: Sensitivity of modelled sulphate and nitrate aerosol to cloud, $\mathrm{pH}$ and ammonia emissions, Atmos. Environ., 43, 3227-3234, 2009.

Rinsland, C. P., Coheur, P. F., Herbin, H., Clerbaux, C., Boone, C., Bernath, P., and Chiou, L. S.: Detection of elevated tropospheric hydrogen peroxide $\left(\mathrm{H}_{2} \mathrm{O}_{2}\right)$ mixing ratios in atmospheric 
chemistry experiment (ACE) subtropical infrared solar occultation spectra, J. Quant. Spectrosc. Radiat. Trans., 107, 340-348, 2007.

Saunders S. M., Jenkin, M. E., Derwent, R. G., and Pilling, M. J.: Protocol for the development of the Master Chemical Mechanism, MCM v3, Part A: tropospheric degradation of nonaromatic volatile organic compounds, Atmos. Chem. Phys., 3, 161-180, doi:10.5194/acp-3-161-2003, 2003.

Savoie, D. L. and Prospero, J. M.: Particle-size distribution of nitrate and sulfate in the marine atmosphere, Geophys. Res. Lett. 9, 1207-1210, 1982.

Stone, D. and Rowley, D. M.: Kinetics of the gas phase $\mathrm{HO}_{2}$ selfreaction: Effects of temperature, pressure, water and methanol vapours, Phys. Chem. Chem. Phys., 7, 2156-2163, 2005.

Tegen, I. and Fung, I.: Modelling of Mineral dust in the Atmosphere-Sources, Transport and Optical-Thickness, J. Geophys. Res.-Atmos., 99, 22897-22914, 1994.

Underwood, G. M., Li. P., Miller, Al-Abadleh, H., and Grassian, V. H.: A Knudsen cell study of the heterogeneous reactivity of nitric acid on oxide and mineral dust particles, J. Phys. Chem. A 105, 6609-6620, 2001.

Usher, C. R., Michel, A. E., and Grassian, V. H.: Reactions on mineral dust, Chem. Rev., 103, 4883-4939, 2003.
Vlasenko, A., Sjogren, S., Weingartner, E., Gaggeler, H. W., and Ammann, M.: Generation of submicron Arizona Test Dust aerosol: chemical and hygroscopic properties, Aerosol Sci. Technol., 39, 452-460, 2005.

Vlasenko, A., Sjogren, S., Weingartner, E., Stemmler, K., and Gaggeler, H. W., and Ammann, M.: Effect of humidity on nitric acid uptake to mineral dust aerosol particles, Atmos. Chem. Phys., 6, 2147-2160, doi:10.5194/acp-6-2147-2006, 2006.

Wagner, C., Hanish, F., Holmes, N., Coninck, H. de., Schuster, G., and Crowley, J. N.: The interaction of $\mathrm{N}_{2} \mathrm{O}_{5}$ with mineral dust: aerosol flow tube and Knudsen reactor studies, Atmos. Chem. Phys., 8, 91-109, doi:10.5194/acp-8-91-2008, 2008.

Zhang, Y. and Carmichael, G. R.: The role of mineral aerosol in tropospheric chemistry in East Asia-a model study, J. Appl. Meteo., 38, 353-366, 1999.

Zhang, Y., Sunwoo, Y., Kotamarthi, V., and Carmichael, G. R.: Photochemical oxidant processes in the presence of dust: An evaluation of the impact of dust on particulate nitrate and ozone formation, J. Appl. Meteo., 33, 813-824, 1994.

Zhu, S., Butler, T., Sander, R., Ma. J., Lawrence, M. G.: Impact of dust on tropospheric photochemistry over polluted regions: a case study of the Beijing megacity, Atmos. Chem. Phys. Discuss., 9, 20145-20194, doi:10.5194/acp-10-3855-2010, 2009. 